\title{
OPEN Effect of welfare standards and biosecurity practices on antimicrobial use in beef cattle
}

\author{
Alessia Diana ${ }^{1 \bowtie}$, Valentina Lorenzi ${ }^{2}$, Mauro Penasa ${ }^{1}$, Edoardo Magni ${ }^{2}$, Giovanni L. Alborali ${ }^{2}$, \\ Luigi Bertocchi ${ }^{2} \&$ Massimo De Marchi ${ }^{1}$
}

Antimicrobial use (AMU) in livestock species and the associated antimicrobial resistance are a global concern, thus strategies for their reduction and a more judicious use are needed. Previous research has revealed a link between improved animal welfare, biosecurity and AMU reduction in pig and dairy sectors, however, little is known about the beef sector. This study aimed to investigate the impact of welfare standards and biosecurity on AMU in beef cattle. Data on performance traits and AMU were collected over a 3.5 year time from 27 specialised beef farms and a treatment incidence was calculated using the defined daily dose for animals. An on-farm assessment was carried out by assigning a score from 0 (very poor) to $100 \%$ (very good) to 3 sections: welfare, biosecurity and emergency management. The highest average score was obtained for the welfare section (76\%) followed by emergency management (39\%) and biosecurity (24\%). This suggests that major focus on strategies for the implementation of biosecurity measures and emergency management is needed, due to the low scores reported. A statistically significant lower AMU was observed with improved level of welfare. These results may be helpful for farm benchmarking and highlight the importance of improved animal welfare for an efficient antimicrobial stewardship.

Animal welfare (welfare) is defined as 'the physical and mental state of an animal in relation to the conditions in which it lives and dies', thus emphasising the importance of biological functioning and natural behavioural needs alike for the assessment of animal well-being ${ }^{2}$. The link between animal health and welfare is widely acknowledged $^{3-5}$ as well as the impact that good welfare may have on animal productivity ${ }^{5,6}$. Indeed, reduced stress levels are essential to avoid an impairment of animals' immune system which in turn would affect their performance and susceptibility to diseases ${ }^{7}$. Similar evidence is also reported for the positive role of improved biosecurity on animal health and welfare. Biosecurity consists of procedures intended to prevent both pathogens entering a farm (external biosecurity) and pathogens spreading within a farm (internal biosecurity $)^{5,8}$. Pandolfi et al. ${ }^{5}$ reported lower prevalence of some disease indicators and negative welfare outcomes, such as severe tail lesions and lameness, in pig farms with high biosecurity and average daily gain (ADG). Ohlson et al. ${ }^{9}$ found an association between lower prevalence of infections with better biosecurity at herd level. In their review, Stokstad et al..$^{10}$ largely discussed about the importance of implementing biosecurity measures to prevent and reduce respiratory diseases in cattle. Hence, both biosecurity and welfare standards are recognized as basic principles of an efficient livestock management ${ }^{8,11,12}$.

Another important aspect of a general farm management is the use of antimicrobials (AMU), since they are useful tools in controlling infectious diseases, especially in intensive farming systems where the spread of pathogens is more likely to occur ${ }^{13-15}$. Despite such an essential role, massive AMU and the associated antimicrobial resistance (AMR) are major concerns worldwide ${ }^{16,17}$. New strategies to advance a more judicious use of medications are needed and providing accurate data on AMU is fundamental to achieve this goal ${ }^{18}$.

Livestock species in EU account for a large proportion of use of antimicrobials ${ }^{19-21}$, making them major contributors to the increase of $\mathrm{AMR}^{16,22,23}$. However, differently from dairy, poultry and swine, only few studies explored the potential risk factors of AMU in the beef sector such as farm size, the duration of the fattening period and quarantine of purchased animals ${ }^{24-26}$. In our previous study on Italian beef cattle ${ }^{27}$, we observed that breed was an important source of variation of AMU with Blonde d'Aquitaine and Limousine being at greater risk of treatment than Charolaise. We also reported a wide variability of AMU among farms suggesting, in

${ }^{1}$ Department of Agronomy, Food, Natural resources, Animals and Environment (DAFNAE), University of Padova, Viale dell'Università 16, 35020 Legnaro (PD), Italy. ${ }^{2}$ Italian National Reference Centre for Animal Welfare, Istituto Zooprofilattico Sperimentale della Lombardia e dell'Emilia Romagna 'Bruno Ubertini' (IZSLER), Via Bianchi 9, 25124 Brescia, Italy. ${ }^{\circledR}$ email: alessiadiana84@gmail.com 
accordance with other studies ${ }^{28,29}$, the role that distinctive farm-factors like welfare and biosecurity procedures or the farmer-veterinarian relationship ${ }^{30}$ may play on the overall AMU.

The European Innovation Partnership for Agricultural Productivity and Sustainability (EIP-AGRI) emphasised that more research is needed to assess the impact of welfare on $\mathrm{AMU}^{31}$. Additionally, there is evidence that high standards of both internal and external biosecurity, and the preventive role played on-farm, may lead to improved animal health and productivity, and in turn to a reduction of $A M U^{32,33}$. For instance, Postma et al. ${ }^{34}$ observed that better biosecurity was linked to a lower AMU in pigs while Raasch et al. ${ }^{35}$ reported a reduction of AMU following the implementation of tailored welfare-friendly procedures on-farm. However, difficulty in applying such changes may be due to farmers' beliefs surrounding use of medications. For instance, the common perception that antimicrobials are essential to preserve animal health and welfare ${ }^{36,37}$ or farmers' opinion that the amount of medications used is low and provided only when necessary ${ }^{38,39}$. As a result, farmers may become reluctant in removing antimicrobials and/or changing certain management procedures. However, some studies confuted this belief reporting how even with a high AMU as part of the common farm management, yet pigs were showing poor welfare conditions and health issues ${ }^{40,41}$. Despite the well-known association between biosecurity, welfare standards and animal health and performance ${ }^{5,10}$, only few studies explored their influence on AMU in beef cattle ${ }^{15,24,42}$. For instance, Becker et al. ${ }^{42}$ reported a drastic reduction of AMU in veal calves following an improvement of those management practices considered as responsible of high AMU (e.g. crowding and suboptimal barn climate conditions).

Every year, $70 \%$ of beef cattle produced in Italy are fattened in specialised fattening farms in Veneto region, in the north-east of the country. Beef producers purchase calves from other EU countries, mostly from France which is the principal supplier and accounts for c. $90 \%$ of imported animals ${ }^{43}$. The main purchased breeds are Charolaise and Limousine, while only a minority of the animals belongs to other breeds such as Salers, Blonde d'Aquitaine or crossbreeds. Calves are weaned in France at pasture and later transferred to Italy for the fattening period. They arrive at the farm at approximately 10-14 months of age and 300 to $400 \mathrm{~kg}$ of weight, and are reared under intensive fattening conditions to reach slaughter weight after an extra period of about 6-7 months. Each farm can have a turnover of about two fattening cycles per year. The typical housing system consist of closed or open barns with multiple pens and fully slatted floors or concrete floors with bedding ${ }^{44}$. All fattening farms operate according to a quite standardized feeding management which supplies a high input in terms of feed. The diet is based on total mixed ration provided with a high proportion of concentrates, different proportions of feedstuffs according to genotype, gender and phase of the fattening cycle, and mineral and vitamin supplementations ${ }^{45}$. Wheat straw and soybean meal are the main sources of fibers and proteins, respectively, whereas corn silage is the principal component of the total mixed ration. Occasionally, dry or pressed ensiled sugar beet pulps are used as non-starchy energy feeds.

Beef cattle reared in intensive farming systems have to deal with several welfare issues during the fattening cycle. Main welfare problems are respiratory and digestive disorders such as the bovine respiratory disease and the sub-acute ruminal acidosis, leading to higher risk of chronic pneumonia, rumen parakeratosis and liver abscesses $^{11}$. These are linked, for instance, to inadequate ventilation systems, inappropriate diets, overstocking and social mixing procedures. These risk factors combined with other potential stressful events/conditions (e.g. weaning, transportation, lack of enrichments or negative animal handling), make intensively reared beef cattle also more susceptible to the development of behavioural problems. Some examples are aggressive behaviour (e.g. fighting and chasing), unusual resting behaviour and fearfulness towards humans which can be a sign of discomfort ${ }^{11}$. Finally, other major detrimental issues in beef production are locomotor disorders such as lameness, bursitis and claw lesions, which mainly compromise the welfare of heavy breeds. Studies showed that the provision of appropriate straw/rubber-bedding areas may be beneficial for the reduction of these injuries ${ }^{46}$.

Therefore, this study aimed to investigate the impact of welfare and biosecurity on AMU in beef cattle. The hypothesis is that higher standards of welfare and biosecurity practices in beef fattening farms are associated to lower levels of AMU. This may become essential for the development of preventive on-farm strategies which in turn might lead to a more prudent antimicrobial stewardship.

\section{Materials and methods}

Data collection. Data used in this study were recorded in specialised Italian fattening farms located in Veneto region by a cooperative of beef producers (AZoVe, Cittadella, Italy) who are the owners of the animals, and covered the period from January 2016 to April 2019. All animals were first purchased from different beef breeding herds by French cattle cooperatives or private companies, and later sold to Italian beef producers. Data collected, initial editing procedure and calculation were performed as described by Diana et al. ${ }^{47}$. The dataset accounted for 1487 batches from 35 beef fattening farms and a total of 87902 animals, with information on farm, sex, breed, body weight, date of beginning and end of the fattening cycle, number of animals and number of casualties. Percentage of animals treated, length of the fattening cycle (days), ADG and mortality rate were calculated per batch which constituted of animals of the same sex and breed. Data of those veterinary medicinal products (VMP, $n=33$ ) containing antimicrobials, which were initially identified by the name of the product and later re-coded by assigning a number from 1 to 33, were recorded as well as the number of parenteral treatments administered to the animals during the study. A defined daily dose for animals was established for each active ingredient with antimicrobial activity of those VMP used in the study. Specifically, the defined daily dose for animals of a VMP represents the dose (in $\mathrm{mg}$ ) of the active ingredient administered per $\mathrm{kg}$ of body weight per day. Finally, data on welfare standards and biosecurity were collected at farm level and matched by batch with all the aforesaid information.

Batches with missing data on welfare, biosecurity, body weight at the beginning and/or at the end of the fattening cycle as well as breeds with less than 20 batches and single-breed farms were discarded from the dataset. 
The final dataset included 1294 batches from 27 beef farms and seven beef breeds: Charolaise, Blonde d'Aquitaine, Limousine, Salers, Italian crossbred, French crossbred and Irish crossbred. A total of 175124 parenteral treatments were administered to the animals during the whole period of study.

Calculation of the treatment incidence 100. Calculation of the treatment incidence 100 (TI100) was also carried out as described by Diana et al. ${ }^{47}$. Defined daily dose for animals were used to calculate the TI100 which quantifies the frequency of treatment and allows for a better monitoring of AMU among countries in livestock farming ${ }^{48,49}$. Specifically, a defined daily dose for animals for Italy (DDDAit) was estimated by using Italian summaries of product characteristics which were established during the development of the ClassyFarm integrated monitoring system (www.classyfarm.it) of the Italian Ministry of Health. The following formula, modified from Timmerman et al. ${ }^{19}$, was used to calculate the treatment incidence 100 for Italy (TI100it) per each VMP ${ }^{50}$ :

$$
\text { TI100it }=\frac{\text { Amount of active ingredient administered per batch }(\mathrm{mg})}{\text { DDDAit }(\mathrm{mg} / \mathrm{kg} / \text { day }) \times \text { Animals at risk } \times \text { Standard weight }(\mathrm{kg}) \times \text { Days at risk }} \times 100
$$

where 'animals at risk' identified the number of animals of the batch; 'standard weight' was the average body weight of animals at treatment $(400 \mathrm{~kg})$ and 'days at risk' is the standard number of days of the fattening cycle (230 days).

The TI100it of each VMP were summed to obtain a total TI100it per batch. A second TI100, namely TI100vet, was calculated using the same formula but replacing the DDDAit with the European Medicines Agency's DDDvet $^{51}$. However, some DDDvet were not included in the TI100vet calculation because they were not available for four active ingredients. Also, two more indexes (HPCIA TI100it and HCPIA TI100vet) were calculated in a similar manner but using only those VMP classified as 'Highest Priority Critically Important Antimicrobials' (HPCIA) because considered as key contributors for the development of $\mathrm{AMR}^{52}$.

Welfare and biosecurity assessment. A welfare farm assessment was carried out once a year at least for 1 year over the period of study by using a modified version of the Italian protocol for the assessment of dairy cow welfare in loose housing systems ${ }^{53}$, which is part of the ClassyFarm monitoring scheme. The protocol was made by a list of 56 items holding information about indicators of animal health and welfare, farm management practices and housing systems (Supplementary Table S1). All items were grouped into three main sections: Total welfare (items from 1 to 42), Biosecurity (items from 43 to 52) and Emergency management (items from 53 to 56). Total welfare section was divided into three areas (Area A: farm management and staff training - items from 1 to 13; Area B: housing - items from 14 to 29; Area C: animal-based measures - items from 30 to 42). Data were collected by 6 trained veterinarians who assigned a score to each item based on a 3-point scale scoring system (from 1 to 3 ) where 1 indicated a high level of risk or else a poor status of the item assessed whereas 3 indicated a low risk or a better status of the item. It is important to highlight that each item had a different 'weight' according to its potential impact on animal health and welfare ${ }^{53}$, so that the score assigned was considered more or less significant in the calculation of the final value. A value for biosecurity, emergency management and each of the three areas of total welfare was calculated per farm by summing the score of those items belonging to each section/area. The value for the section total welfare was calculated as reported in Ginestreti et al. ${ }^{54}$, considering a $50 \%$ contribution by Areas A and B and the remaining $50 \%$ by Area C. All these values were then expressed into percentage from 0 to 100 where zero indicated a poor status (i.e. lack of any welfare/biosecurity measures) and 100 indicated a good status (i.e. full application of welfare/biosecurity measures). Data on total welfare, Areas A, $\mathrm{B}$ and $\mathrm{C}$, biosecurity and emergency management were re-coded into three categories each as for the guidelines of the Italian welfare protocol: low, medium and high. Specifically, a value up to $59 \%$ corresponded to a poor status of the section (i.e. low), from 60 to $80 \%$ to a medium status (i.e. medium) and above $80 \%$ to a good status (i.e. high). Finally, data obtained from the welfare farm assessment were matched with data on AMU and all the aforesaid information by assigning to the batches of each farm the associated score calculated for each section.

Statistical analysis. Data were analysed using SAS 9.4 (SAS Institute Inc., Cary, NC, USA) with batch as experimental unit and were checked for normality using the Shapiro-Wilk test, skewness and kurtosis, and visual inspection of the normal plot. Pearson correlations were used to investigate the relationships between the three sections of the on-farm assessment (i.e. total welfare, biosecurity and emergency management) and between the three areas of total welfare section (i.e. Area A, B and C). Results are presented as the correlation coefficient (Rho). An ANOVA test in GLM procedure of SAS was used to check for: 1) statistical differences among years and breeds for total welfare, biosecurity and emergency management scores; 2) statistical differences among categories of total welfare, biosecurity and emergency management for performance traits and length of the fattening cycle. All TI100 indexes were not normally distributed, thus a generalized linear mixed model with gamma distribution and log link function in GLIMMIX procedure of SAS was used to investigate whether welfare standards and biosecurity practices are sources of variation of the aforesaid indexes. Data on total welfare, Areas B and $\mathrm{C}$, biosecurity and emergency management were available for two of the three categories (low, medium and high), whereby the missing category was not included in the final analysis. The model accounted for sex, season, total welfare (two categories: medium, high), biosecurity (two categories: low, medium), emergency management (two categories: low, high) and the interaction between total welfare and sex as fixed effects, and farm and breed as random effects. In addition, a second model was used to check the effect of each welfare area on the TI100 indexes by substituting the variable total welfare with Area A (three categories: low, medium, high), B (two categories: low, medium) and C (two categories: medium, high) as predictors. Results are presented as least squares means (LSM) \pm standard error of the mean (SEM). A Tukey-Kramer adjustment was used to account for 


\begin{tabular}{|c|c|c|c|c|c|c|c|c|c|c|c|c|c|c|c|c|c|}
\hline \multirow[b]{2}{*}{ Item } & \multirow[b]{2}{*}{ Category } & \multicolumn{4}{|c|}{ Animals per batch (n) } & \multicolumn{4}{|c|}{ Mortality rate (\%) } & \multicolumn{4}{|c|}{ Animals treated (n) } & \multicolumn{4}{|c|}{ Animals treated (\%) } \\
\hline & & Mean & SD & Min & Max & Mean & SD & Min & Max & Mean & SD & Min & Max & Mean & SD & Min & Max \\
\hline \multirow{3}{*}{ Total welfare } & Low $(<60 \%)$ & \multicolumn{4}{|l|}{ NA } & \multicolumn{4}{|l|}{ NA } & \multicolumn{4}{|l|}{ NA } & \multicolumn{4}{|l|}{ NA } \\
\hline & $\begin{array}{l}\text { Medium (60\% to } \\
80 \%)\end{array}$ & 60.76 & 34.39 & 15.0 & 220.0 & 0.74 & 1.51 & 0.0 & 15.56 & 40.79 & 34.99 & 1.0 & 219.0 & 64.79 & 39.03 & 1.45 & 100 \\
\hline & High $(>80 \%)$ & 56.35 & 36.25 & 15.0 & 170.0 & 0.46 & 1.37 & 0.0 & 11.11 & 34.80 & 34.55 & 1.0 & 150.0 & 63.46 & 39.35 & 1.32 & 100 \\
\hline \multirow{3}{*}{ Area A } & Low $(<60 \%)$ & 55.59 & 25.87 & 20.0 & 121.0 & 0.37 & 1.13 & 0.0 & 5.00 & 42.48 & 33.88 & 1.0 & 121.0 & 70.49 & 36.26 & 2.86 & 100 \\
\hline & $\begin{array}{l}\text { Medium }(60 \% \text { to } \\
80 \%)\end{array}$ & 57.49 & 34.06 & 15.0 & 220.0 & 0.71 & 1.48 & 0.0 & 12.77 & 39.74 & 34.32 & 1.0 & 219.0 & 67.13 & 38.70 & 1.45 & 100 \\
\hline & High $(>80 \%)$ & 69.31 & 34.43 & 15.0 & 176.0 & 0.62 & 1.56 & 0.0 & 15.56 & 39.07 & 37.48 & 1.0 & 176.0 & 54.42 & 39.22 & 1.32 & 100 \\
\hline \multirow{3}{*}{ Area B } & Low $(<60 \%)$ & 58.91 & 35.09 & 15.0 & 220.0 & 0.71 & 1.58 & 0.0 & 15.56 & 38.51 & 35.08 & 1.0 & 219.0 & 63.82 & 39.46 & 1.45 & 100 \\
\hline & $\begin{array}{l}\text { Medium (60\% to } \\
80 \%)\end{array}$ & 62.35 & 32.44 & 15.0 & 203.0 & 0.63 & 1.25 & 0.0 & 9.68 & 42.42 & 34.60 & 1.0 & 176.0 & 66.26 & 38.16 & 1.32 & 100 \\
\hline & High $(>80 \%)$ & \multicolumn{4}{|l|}{ NA } & \multicolumn{4}{|l|}{ NA } & \multicolumn{4}{|l|}{ NA } & \multicolumn{4}{|l|}{ NA } \\
\hline \multirow{3}{*}{ Area C } & Low $(<60 \%)$ & \multicolumn{4}{|l|}{ NA } & \multicolumn{4}{|l|}{ NA } & \multicolumn{4}{|l|}{ NA } & \multicolumn{4}{|l|}{ NA } \\
\hline & $\begin{array}{l}\text { Medium (60\% to } \\
80 \%)\end{array}$ & 60.08 & 35.34 & 15.0 & 220.0 & 1.09 & 1.69 & 0.0 & 9.68 & 37.72 & 32.27 & 1.0 & 210.0 & 61.19 & 38.42 & 2.86 & 100 \\
\hline & High $(>80 \%)$ & 59.88 & 33.98 & 15.0 & 219.0 & 0.56 & 1.40 & 0.0 & 15.56 & 40.27 & 35.77 & 1.0 & 219.0 & 65.58 & 39.24 & 1.32 & 100 \\
\hline \multirow{3}{*}{ Biosecurity } & Low $(<60 \%)$ & 60.64 & 34.37 & 15.0 & 220.0 & 0.68 & 1.48 & 0.0 & 15.56 & 40.09 & 35.24 & 1.0 & 219.0 & 64.20 & 39.07 & 1.32 & 100 \\
\hline & $\begin{array}{l}\text { Medium (60\% to } \\
80 \%)\end{array}$ & 30.87 & 10.71 & 15.0 & 56.0 & 0.86 & 1.92 & 0.0 & 6.67 & 22.32 & 12.20 & 2.0 & 54.0 & 78.53 & 37.53 & 6.67 & 100 \\
\hline & High $(>80 \%)$ & \multicolumn{4}{|l|}{ NA } & \multicolumn{4}{|l|}{ NA } & \multicolumn{3}{|l|}{ NA } & & \multicolumn{4}{|l|}{ NA } \\
\hline \multirow{3}{*}{$\begin{array}{l}\text { Emergency manage- } \\
\text { ment }\end{array}$} & Low $(<60 \%)$ & 60.42 & 34.46 & 15.0 & 220.0 & 0.68 & 1.49 & 0.0 & 15.56 & 40.24 & 35.05 & 1.0 & 219.0 & 65.23 & 38.94 & 1.32 & 100 \\
\hline & $\begin{array}{l}\text { Medium (60\% to } \\
80 \%)\end{array}$ & \multicolumn{4}{|l|}{ NA } & \multicolumn{4}{|l|}{ NA } & NA & & & & NA & & & \\
\hline & High $(>80 \%)$ & 35.69 & 4.99 & 28.0 & 50.0 & 0.89 & 1.36 & 0.0 & 3.03 & 11.35 & 12.28 & 1.0 & 50.0 & 30.90 & 30.46 & 2.86 & 100 \\
\hline
\end{tabular}

Table 1. Descriptive statistics of number of animals per batch, mortality rate, number and percentage of animals treated for each category (low, medium and high) of total welfare, Area A, Area B, Area C, biosecurity and emergency management. NA, no batch felt within the category; SD, standard deviation.

multiple comparisons. The criterion for determination of statistical significance was established at $\mathrm{P}<0.05$ while statistical trend was established at $0.05>\mathrm{P}<0.10$.

Ethics approval. This study was approved by the Ethical Committee for the Care and Use of Experimental Animals of the University of Padova, Italy (approval no. 74/2018). The study was conducted in accordance with Italian law (Decreto legislativo no. 26/2014) and EU Directive 2010/63/EU on the protection of animals used for scientific purposes.

\section{Results}

Performance traits and length of the fattening cycle per categories of welfare, biosecurity and emergency management. The average farm had 596.8 heads $(S D=295.9)$. Average batch size for total welfare was 56.3 vs. 60.7 heads (categories high and medium, respectively), 30.9 vs. 60.6 heads for biosecurity (categories medium and low, respectively) and 35.7vs. 60.4 heads for emergency management (categories high and low, respectively; Table 1). Percentage of animals treated was 63.5 vs. $64.8 \%$ (categories high and medium, respectively) for total welfare, 30.9 vs. $65.2 \%$ (high and low, respectively) for emergency management and 78.5 vs. $64.2 \%$ (medium and low, respectively) for biosecurity. Descriptive data of the 3 areas of total welfare are reported in Table 1. Performance traits and length of the fattening cycle were significantly different between categories of welfare, biosecurity and emergency management $(\mathrm{P}<0.05)$ and between the 3 areas of total welfare $(\mathrm{P}<0.05)$ except for the initial body weight between categories of biosecurity and ADG between categories of Area B ( $>0.05$; Table 2). The lowest initial body weight was reported for the highest category of total welfare ( 337.4 vs. $354.5 \mathrm{~kg}$ for categories high and medium, respectively), biosecurity (333.8 vs. $351.7 \mathrm{~kg}$ for medium and low, respectively) and emergency management (324.8 vs. $351.8 \mathrm{~kg}$ for high and low, respectively). Similar patterns were observed for the final body weight between categories of total welfare and emergency management, but not for biosecurity where the lowest final body weight was observed for the category low (634.9 vs. $656.8 \mathrm{~kg}$ for low and medium, respectively). The number of days spent in the production cycle was lower for the highest category of total welfare (200.3 vs. $205.1 \mathrm{~d}$ for high and medium, respectively), while the opposite result was observed for biosecurity (213.0 vs. $203.9 \mathrm{~d}$ for medium and low, respectively) and emergency management (247.1 vs. $203.3 \mathrm{~d}$ for high and low, respectively; Table 2).

Total welfare, biosecurity and emergency management data. Overall, 59.3\% of the farms were assessed for 3 years, $22.2 \%$ of the farms for 2 years and $18.5 \%$ of the farms for 1 year. Total welfare per batch ranged from 66 to $84 \%$ (mean $=76 \%, S D=5 \%)$, biosecurity ranged from 9 to $66 \%$ (mean $=24 \%, S D=12 \%)$ and emergency management from 14 to $83 \%$ (mean $=39 \%, S D=20 \%$ ). Data obtained for the 3 areas of total welfare 


\begin{tabular}{|c|c|c|c|c|c|c|c|c|c|c|c|c|c|c|c|c|c|}
\hline \multirow[b]{2}{*}{ Item } & \multirow[b]{2}{*}{ Category } & \multicolumn{4}{|c|}{ Average daily gain (kg/d) } & \multicolumn{4}{|c|}{ Initial body weight (kg) } & \multicolumn{4}{|c|}{ Final body weight (kg) } & \multicolumn{4}{|c|}{ Length of fattening cycle (d) } \\
\hline & & Mean & SD & Min & Max & Mean & SD & Min & Max & Mean & SD & Min & Max & Mean & SD & Min & Max \\
\hline \multirow{3}{*}{$\begin{array}{l}\text { Total } \\
\text { welfare }\end{array}$} & Low $(<60 \%)$ & \multicolumn{4}{|l|}{ NA } & \multicolumn{4}{|l|}{ NA } & \multicolumn{4}{|l|}{ NA } & \multicolumn{4}{|l|}{ NA } \\
\hline & \begin{tabular}{|l|} 
Medium \\
$(60 \%$ to \\
$80 \%)$
\end{tabular} & 1.40 & 0.27 & 0.22 & 2.38 & 354.5 & 60.1 & 187.0 & 535.0 & 641.3 & 86.9 & 409.7 & 798.5 & 205.1 & 29.5 & 98.2 & 338.7 \\
\hline & \begin{tabular}{|l}
$\begin{array}{l}\text { High } \\
(>80 \%)\end{array}$ \\
\end{tabular} & 1.37 & 0.28 & 0.39 & 1.80 & 337.4 & 58.4 & 222.0 & 630.1 & 610.7 & 95.8 & 395.1 & 786.9 & 200.3 & 21.0 & 90.6 & 307.0 \\
\hline \multirow{3}{*}{ Area A } & Low $(<60 \%)$ & 1.39 & 0.28 & 0.98 & 1.86 & 326.9 & 58.5 & 243.3 & 414.7 & 626.2 & 94.5 & 475.3 & 743.2 & 218.2 & 37.7 & 181.0 & 325.2 \\
\hline & \begin{tabular}{|l|} 
Medium \\
$(60 \%$ to \\
$80 \%)$
\end{tabular} & 1.36 & 0.28 & 0.22 & 2.38 & 346.4 & 58.8 & 187.0 & 630.1 & 625.1 & 90.8 & 395.1 & 798.5 & 205.3 & 28.6 & 90.6 & 338.7 \\
\hline & \begin{tabular}{|l}
$\begin{array}{l}\text { High } \\
(>80 \%)\end{array}$ \\
\end{tabular} & 1.51 & 0.19 & 0.80 & 2.07 & 372.1 & 60.2 & 237.0 & 520.4 & 674.5 & 71.8 & 469.5 & 786.9 & 198.6 & 24.4 & 122.3 & 280.4 \\
\hline \multirow{3}{*}{ Area B } & Low $(<60 \%)$ & 1.39 & 0.27 & 0.22 & 2.38 & 357.4 & 61.3 & 187.0 & 535.0 & 643.5 & 90.1 & 395.1 & 798.5 & 205.8 & 29.7 & 98.2 & 338.7 \\
\hline & \begin{tabular}{|l|} 
Medium \\
$(60 \%$ to \\
$80 \%)$
\end{tabular} & 1.39 & 0.26 & 0.34 & 1.89 & 336.8 & 54.5 & 203.9 & 630.1 & 616.5 & 85.3 & 409.7 & 785.1 & 200.3 & 23.7 & 90.6 & 316.9 \\
\hline & \begin{tabular}{|l}
$\begin{array}{l}\text { High } \\
(>80 \%)\end{array}$ \\
\end{tabular} & \multicolumn{4}{|l|}{ NA } & \multicolumn{4}{|l|}{ NA } & \multicolumn{4}{|l|}{$\mathrm{NA}$} & \multicolumn{4}{|l|}{ NA } \\
\hline \multirow{3}{*}{ Area C } & Low $(<60 \%)$ & \multicolumn{4}{|l|}{ NA } & \multicolumn{4}{|l|}{ NA } & \multicolumn{4}{|l|}{ NA } & \multicolumn{4}{|l|}{ NA } \\
\hline & \begin{tabular}{|l|} 
Medium \\
$(60 \%$ to \\
$80 \%)$
\end{tabular} & 1.41 & 0.27 & 0.34 & 2.07 & 355.3 & 65.1 & 211.0 & 520.4 & 638.3 & 85.1 & 409.7 & 788.9 & 199.3 & 27.3 & 122.3 & 298.3 \\
\hline & \begin{tabular}{|l|} 
High \\
$(>80 \%)$
\end{tabular} & 1.39 & 0.27 & 0.22 & 2.38 & 350.5 & 58.5 & 187.0 & 630.1 & 634.6 & 90.5 & 395.1 & 798.5 & 205.7 & 28.3 & 90.6 & 338.7 \\
\hline \multirow{3}{*}{$\begin{array}{l}\text { Biosecu- } \\
\text { rity }\end{array}$} & Low $(<60 \%)$ & 1.39 & 0.27 & 0.22 & 2.38 & 351.7 & 60.1 & 187.0 & 630.1 & 634.9 & 89.7 & 395.1 & 798.5 & 203.9 & 28.2 & 90.6 & 338.7 \\
\hline & \begin{tabular}{|l|} 
Medium \\
$(60 \%$ to \\
$80 \%)$
\end{tabular} & 1.52 & 0.18 & 0.80 & 1.78 & 333.8 & 61.5 & 248.0 & 492.0 & 656.8 & 77.3 & 469.5 & 786.9 & 213.0 & 23.8 & 156.5 & 261.2 \\
\hline & \begin{tabular}{|l} 
High \\
$(>80 \%)$
\end{tabular} & \multicolumn{4}{|l|}{ NA } & \multicolumn{4}{|l|}{ NA } & \multicolumn{4}{|l|}{ NA } & \multicolumn{4}{|l|}{ NA } \\
\hline \multirow{3}{*}{$\begin{array}{l}\text { Emer- } \\
\text { gency } \\
\text { manage- } \\
\text { ment }\end{array}$} & Low $(<60 \%)$ & 1.40 & 0.26 & 0.22 & 2.38 & 351.8 & 60.6 & \begin{tabular}{|l|}
187.0 \\
\end{tabular} & 630.1 & 637.2 & 89.4 & 395.1 & 798.5 & 203.3 & 27.6 & 90.6 & 338.7 \\
\hline & \begin{tabular}{|l|l|} 
Medium \\
$(60 \%$ to \\
$80 \%)$ \\
\end{tabular} & \multicolumn{4}{|l|}{ NA } & \multicolumn{4}{|l|}{ NA } & NA & & & & NA & & & \\
\hline & \begin{tabular}{|l|} 
High \\
$(>80 \%)$
\end{tabular} & 0.89 & 0.15 & 0.34 & 1.09 & 324.8 & 12.1 & 301.0 & 348.0 & 550.6 & 34.2 & 477.3 & 600.5 & 247.1 & 24.1 & 197.7 & 284.4 \\
\hline
\end{tabular}

Table 2. Means and standard deviation (SD) of performance traits and number of days spent in the fattening cycle for each category (low, medium and high) of total welfare, Area A, Area B, Area C, biosecurity and emergency management. NA = no batch felt within the category.

ranged from 59 to $86 \%$ (mean $=74 \%, \mathrm{SD}=6 \%$ ) for Area $\mathrm{A}$ (farm management and staff training), 40 to $75 \%$ (mean $=56 \%, \mathrm{SD}=8 \%$ ) for Area B (housing) and 63 to $100 \%$ (mean $=87 \%, \mathrm{SD}=9 \%$ ) for Area C (animal-based measures). Specifically, a considerable variability was observed between the 27 farms for biosecurity and emergency management (Fig. 1).

Correlations between total welfare, biosecurity and emergency management and between the 3 areas of total welfare are presented in Table 3. Specifically, total welfare and biosecurity were positively correlated $($ Rho $=0.31)$ while low correlations were found for total welfare and emergency management $(\mathrm{Rho}=-0.17)$ and for biosecurity and emergency management $(\mathrm{R}=0.20)$. Total welfare, biosecurity and emergency management scores were significantly different among years $(\mathrm{P}<0.001$; Fig. 2$)$ and breeds $(\mathrm{P}<0.01$; Table 4$)$ except for biosecurity that tended to be different among breeds $(\mathrm{P}=0.079)$.

Effect of welfare, biosecurity and emergency management on the treatment incidence. Antimicrobial use differed significantly between categories of total welfare. Specifically, lower AMU was observed with higher welfare conditions (> 80\%) for TI100it (1.25 vs. 1.61 for high and medium categories, respectively; $\mathrm{P}=0.008)$ and TI100vet (1.02 vs. 1.28 for high and medium, respectively; $\mathrm{P}=0.021)$ whereas, despite a similar trend, no differences were reported for the corresponding HPCIA indexes $(\mathrm{P}>0.05$; Table 5). No significant differences were reported between categories of biosecurity and emergency management for the investigated TI100 indexes.

No significant differences were also observed between categories of Area A, Area B and Area C of total welfare for the TI100it and the TI100vet $(\mathrm{P}>0.05$; Table 6). No significant differences between categories of Area A, Area $\mathrm{B}$ and Area $\mathrm{C}$ of total welfare were also observed for the HPCIA TI100it $(\mathrm{P}>0.05)$, whereas lower AMU was observed with higher welfare in Area A only for the HPCIA TI100vet $(\mathrm{P}=0.034$; Table 6). 

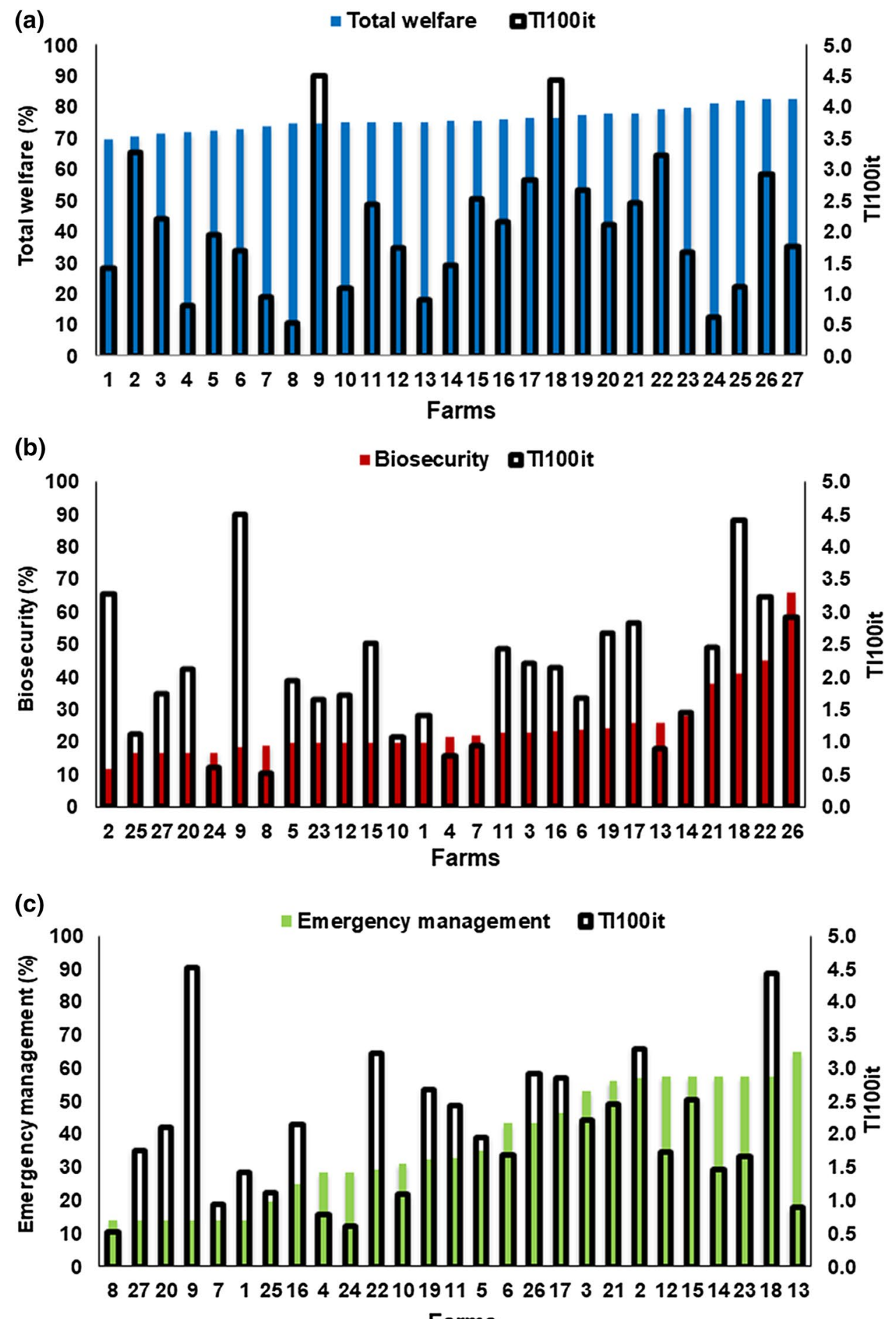

Farms

Figure 1. Descriptive statistics of the score of (a) total welfare, (b) biosecurity, (c) emergency management and TI100 it ${ }^{1}$ of beef farms included in the study $(n=27) .{ }^{1}$ TI100it = treatment incidence 100 for Italy, calculated by using the defined daily dose for animals for Italy based on Italian guidelines of dosage obtained from the Italian database (www.classyfarm.it).

Finally, breeds tended to be different for all TI100 indexes: TI100it $(0.119 \pm 0.073 ; \mathrm{P}=0.052)$, TI100vet $(0.113 \pm 0.073 ; \mathrm{P}=0.061)$, HPCIA TI100it $(0.194 \pm 0.123 ; \mathrm{P}=0.058)$ and HPCIA TI100vet $(0.118 \pm 0.082 ; \mathrm{P}=0.074)$ indicating a substantial variability of AMU among breeds (Table 7). 


\begin{tabular}{|l|l|l|l|l|l|}
\hline Item & $\mathbf{1}$ & $\mathbf{2}$ & $\mathbf{3}$ & $\mathbf{4}$ & $\mathbf{5}$ \\
\hline Total welfare, 1 & & & & & \\
\hline Biosecurity, 2 & $0.31^{* *}$ & & & & \\
\hline Emergency management, 3 & $-0.17^{* *}$ & $0.20^{* *}$ & & & \\
\hline Area A, 4 & $0.65^{* *}$ & $0.29^{* *}$ & $-0.11^{*}$ & & \\
\hline Area B, 5 & $0.53^{\star}$ & $0.19^{* *}$ & $-0.06^{*}$ & $-0.11^{* *}$ & \\
\hline Area C, 6 & $0.88^{* *}$ & $0.17^{* *}$ & $-0.13^{* *}$ & $0.44^{* *}$ & $-0.35^{*}$ \\
\hline
\end{tabular}

Table 3. Pearson correlations between the average score (\%) of total animal welfare, biosecurity, emergency management and the 3 areas of total welfare (Area A, B and C) in beef cattle. ${ }^{1}$ Total welfare $=$ this section consists of variables grouped and listed within Area A, Area B and Area C (Supplementary Table S1). ${ }^{2}$ Biosecurity $=$ some examples of the variables included are control of visitors, quarantine, control of rodents and lorry cleaning (Supplementary Table S1). ${ }^{3}$ Emergency management = variables included are fire alarm, ventilation alarm, risk of noise and source of drinking water (Supplementary Table S1). ${ }^{4}$ Area $A=$ farm management and staff training (e.g. feeding, cleaning, n. of employees, n. of animal inspections; Supplementary Table S1). ${ }^{5}$ Area B = housing (e.g. flooring system, lighting system, hospital pen; Supplementary Table S1). ${ }^{6}$ Area $\mathrm{C}=$ animal-based measures (e.g. respiratory disease, human-animal interaction, aggressive behaviour, lesions, lameness; Supplementary Table S1). ${ }^{\star} \mathrm{P}<0.05 ;{ }^{*} \mathrm{P}<0.001$.

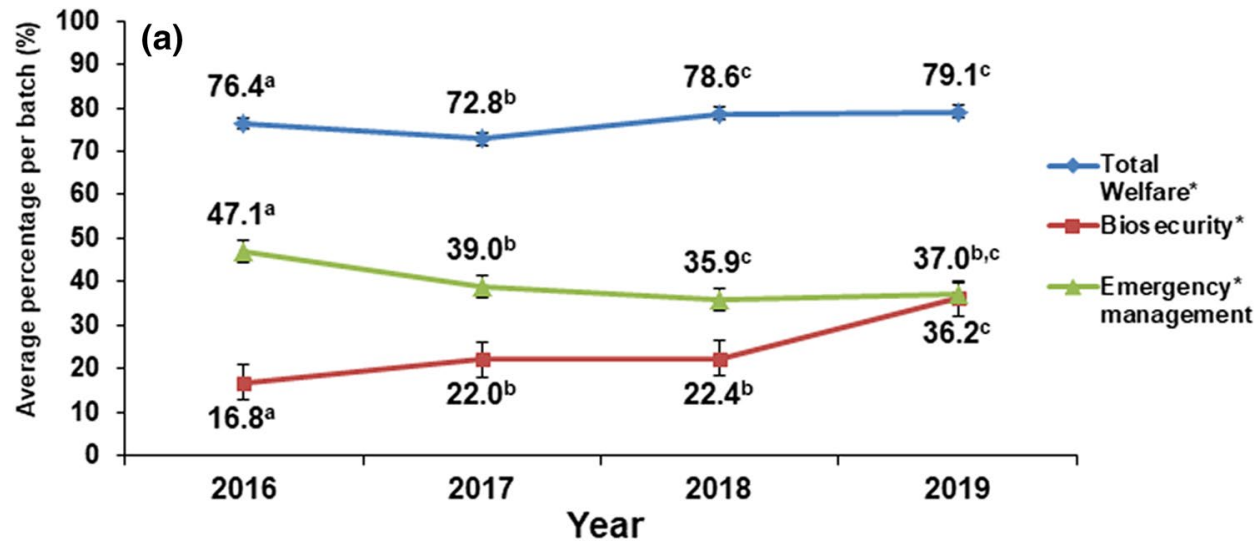

(b)

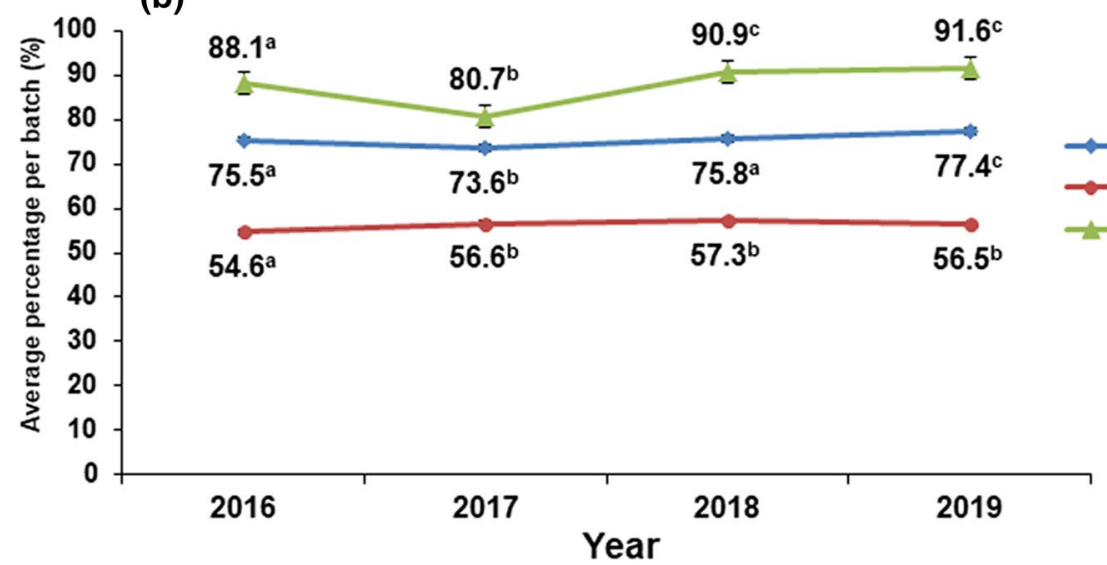

Figure 2. Average percentage (\%) of the score of (a) total welfare, biosecurity and emergency management and of (b) Area A, Area B and Area C of total welfare among years in beef cattle. ${ }^{\mathrm{a}, \mathrm{b}}$ Different superscript letters within each sector (e.g. total welfare, biosecurity and emergency management) and area (Area A, B and C) indicate significant differences $(\mathrm{P}<0.05)$. $^{*} \mathrm{P}<0.001$.

\section{Discussion}

The objective of this study was to investigate whether some representative farm factors such as welfare standards and biosecurity practices may be identified as sources of variation of AMU in beef cattle. Previous studies reported that typical farm factors such as management practices, farm size, feeding and housing systems or tailored welfare-friendly procedures are likely to affect AMU $24,35,36,55,56$. Therefore, the variability of levels of 


\begin{tabular}{|c|c|c|c|c|c|c|c|c|c|c|c|c|c|c|c|}
\hline \multirow[b]{2}{*}{ Item } & \multicolumn{2}{|l|}{ BDA } & \multicolumn{2}{|l|}{ CHR } & \multicolumn{2}{|l|}{ FRC } & \multicolumn{2}{|l|}{ IRC } & \multicolumn{2}{|l|}{ ITC } & \multicolumn{2}{|l|}{ LIM } & \multicolumn{2}{|l|}{ SAL } & \multirow[b]{2}{*}{$P$ value } \\
\hline & LSM & SEM & LSM & SEM & LSM & SEM & LSM & SEM & LSM & SEM & LSM & SEM & LSM & SEM & \\
\hline Total welfare ${ }^{2}$ & $77.78^{\mathrm{b}, \mathrm{d}}$ & 0.93 & $77.08^{\mathrm{c}, \mathrm{d}}$ & 0.18 & $75.83^{\mathrm{a}, \mathrm{b}}$ & 0.47 & $77.75^{\mathrm{c}, \mathrm{d}}$ & 0.84 & $75.24^{\mathrm{a}}$ & 0.49 & $76.79^{\mathrm{b}, \mathrm{c}}$ & 0.27 & $76.81^{\mathrm{a}, \mathrm{b}, \mathrm{d}}$ & 0.90 & 0.003 \\
\hline Area $\mathrm{A}^{3}$ & $76.60^{\mathrm{b}, c, \mathrm{~d}}$ & 1.33 & $75.22^{\mathrm{b}, \mathrm{c}}$ & 0.26 & $74.92^{\mathrm{a}, \mathrm{b}}$ & 0.68 & $75.38^{\mathrm{a}, \mathrm{c}}$ & 1.20 & $73.21^{\mathrm{a}}$ & 0.70 & $73.63^{\mathrm{a}}$ & 0.38 & $80.05^{\mathrm{d}}$ & 1.29 & $<0.001$ \\
\hline Area $B^{4}$ & $60.11^{\mathrm{c}, \mathrm{d}}$ & 1.65 & $55.37^{\mathrm{b}}$ & 0.32 & $51.15^{\mathrm{a}}$ & 0.84 & $55.92^{\mathrm{b}, \mathrm{c}}$ & 1.49 & $54.73^{\mathrm{b}}$ & 0.87 & $58.47^{\mathrm{c}, \mathrm{d}}$ & 0.47 & $58.08^{\mathrm{b}, \mathrm{d}}$ & 1.60 & $<0.001$ \\
\hline Area $C^{5}$ & $87.41^{\mathrm{a}, \mathrm{c}}$ & 1.65 & $89.12^{\mathrm{c}}$ & 0.32 & $88.92^{\mathrm{b}, \mathrm{d}, \mathrm{d}}$ & 0.84 & $90.08^{\mathrm{c}, \mathrm{d}}$ & 1.49 & $86.74^{\mathrm{a}, \mathrm{b}}$ & 0.87 & $87.74^{\mathrm{a}, \mathrm{d}}$ & 0.47 & $84.83^{\mathrm{a}}$ & 1.60 & 0.005 \\
\hline Biosecurity $^{6}$ & $23.74^{\mathrm{a}, \mathrm{b}}$ & 2.53 & $26.28^{\mathrm{b}, \mathrm{c}, \mathrm{d}, \mathrm{e}}$ & 0.49 & $24.46^{\mathrm{a}, \mathrm{d}}$ & 1.29 & $24.87^{\mathrm{a}, \mathrm{e}}$ & 2.29 & $24.35^{\mathrm{a}, \mathrm{c}}$ & 1.34 & $26.62^{\mathrm{b}, c, \mathrm{~d}, \mathrm{e}}$ & 0.73 & $20.06^{\mathrm{a}}$ & 2.45 & 0.079 \\
\hline $\begin{array}{l}\text { Emergency }{ }^{7} \text { man- } \\
\text { agement }\end{array}$ & $56.24^{\mathrm{e}}$ & 4.26 & $39.44^{\mathrm{b}}$ & 0.83 & $44.76^{\mathrm{c}, \mathrm{d}}$ & 2.17 & $39.16^{\mathrm{b}, \mathrm{c}}$ & 3.85 & $39.38^{\mathrm{b}, \mathrm{d}}$ & 2.25 & $38.18^{\mathrm{b}}$ & 1.22 & $21.09^{\mathrm{a}}$ & 4.13 & $<0.001$ \\
\hline
\end{tabular}

Table 4. Least squares means (LSM) and standard error of the mean (SEM) of the average score (\%) of total welfare, biosecurity, emergency management and the 3 areas of total welfare (Area A, B and C) by breeds ${ }^{1}$ in beef cattle. ${ }^{\mathrm{a}, \mathrm{b}}$ Different superscript letters between breeds within each sector or area indicate significant differences $(\mathrm{P}<0.05) .{ }^{1} \mathrm{BDA}=$ Blonde d'Aquitaine, $\mathrm{CHR}=$ Charolaise, $\mathrm{FRC}=$ French crossbred, IRC $=$ Irish crossbred, ITC $=$ Italian crossbred, $\mathrm{LIM}=$ Limousine, $\mathrm{SAL}=$ Salers.${ }^{2}$ Total welfare $=$ this section consists of variables grouped and listed within Area A, Area B and Area C (Supplementary Table S1). ${ }^{3}$ Area $\mathrm{A}=$ farm management and staff training (e.g. feeding, cleaning, $\mathrm{n}$. of employees, $\mathrm{n}$. of animal inspections; Supplementary Table S1). ${ }^{4}$ Area B = housing (e.g. flooring system, lighting system, hospital pen; Supplementary Table S1). ${ }^{5}$ Area $\mathrm{C}=$ animal-based measures (e.g. respiratory disease, human-animal interaction, aggressive behaviour, lesions, lameness; Supplementary Table S1). ${ }^{6}$ Biosecurity $=$ some examples of the variables included are control of visitors, quarantine, control of rodents and lorry cleaning (Supplementary Table S1). ${ }^{7}$ Emergency management $=$ variables included are fire alarm, ventilation alarm, risk of noise and source of drinking water (Supplementary Table S1).

\begin{tabular}{|c|c|c|c|c|c|c|c|c|c|}
\hline \multirow[b]{2}{*}{ Effect } & \multirow[b]{2}{*}{ Category } & \multicolumn{2}{|c|}{ TI100it } & \multicolumn{2}{|c|}{ TI100vet } & \multicolumn{2}{|c|}{$\begin{array}{l}\text { HPCIA } \\
\text { TI100it }\end{array}$} & \multicolumn{2}{|c|}{$\begin{array}{l}\text { HPCIA } \\
\text { TI100vet }\end{array}$} \\
\hline & & LSM & SEM & LSM & SEM & LSM & SEM & LSM & SEM \\
\hline \multirow{3}{*}{ Total welfare ${ }^{2}$} & Low $(<60 \%)$ & NA & NA & NA & NA & NA & NA & NA & NA \\
\hline & Medium (60\% to $80 \%)$ & $1.61^{\mathrm{a}}$ & 0.45 & $1.28^{\mathrm{a}}$ & 0.42 & $0.98^{\mathrm{a}}$ & 0.34 & $0.89^{\mathrm{a}}$ & 0.37 \\
\hline & High $(>80 \%)$ & $1.25^{\mathrm{b}}$ & 0.35 & $1.02^{\mathrm{b}}$ & 0.34 & $0.81^{\mathrm{a}}$ & 0.28 & $0.75^{\mathrm{a}}$ & 0.32 \\
\hline \multirow{3}{*}{ Biosecurity $^{3}$} & Low $(<60 \%)$ & $1.24^{\mathrm{a}}$ & 0.23 & $0.87^{\mathrm{a}}$ & 0.17 & $0.71^{\mathrm{a}}$ & 0.17 & $0.58^{\mathrm{a}}$ & 0.14 \\
\hline & Medium (60\% to $80 \%)$ & $1.63^{\mathrm{a}}$ & 0.76 & $1.51^{\mathrm{a}}$ & 0.87 & $1.12^{\mathrm{a}}$ & 0.65 & $1.14^{\mathrm{a}}$ & 0.88 \\
\hline & High $(>80 \%)$ & NA & NA & NA & NA & NA & NA & NA & NA \\
\hline \multirow{3}{*}{ Emergency management ${ }^{4}$} & Low $(<60 \%)$ & $1.62^{\mathrm{a}}$ & 0.42 & $1.31^{\mathrm{a}}$ & 0.40 & $1.05^{\mathrm{a}}$ & 0.34 & $0.94^{\mathrm{a}}$ & 0.38 \\
\hline & Medium (60\% to $80 \%)$ & NA & NA & NA & $\mathrm{NA}$ & NA & $\mathrm{NA}$ & NA & NA \\
\hline & High $(>80 \%)$ & $1.25^{\mathrm{a}}$ & 0.40 & $1.00^{\mathrm{a}}$ & 0.36 & $0.76^{\mathrm{a}}$ & 0.30 & $0.71^{\mathrm{a}}$ & 0.33 \\
\hline
\end{tabular}

Table 5. Least squares means (LSM) and standard error of the mean (SEM) of the treatment incidence $(\mathrm{TI} 100)^{1}$ for the effects of total welfare, biosecurity and emergency management in beef cattle. ${ }^{\mathrm{a}, \mathrm{b}}$ Different superscript letters within each TI100 index and effect indicate significant differences $(\mathrm{P}<0.05)$; NA = no batch felt within the category. ${ }^{1}$ TI100it = treatment incidence 100 for Italy, calculated by using the defined daily dose for animals for Italy based on Italian guidelines of dosage obtained from the Italian database (http://www.classyfarm.it); TI100vet=treatment incidence 100 for EU, calculated by using the defined daily dose for animals for Europe based on EMA' guidelines of dosage ${ }^{51}$; HPCIA = Highest Priority Critically Important Antimicrobials. ${ }^{2}$ Total welfare $=$ this section consists of variables grouped and listed within Area A, Area B and Area C (Supplementary Table S1). ${ }^{3}$ Biosecurity $=$ some examples of the variables included are control of visitors, quarantine, control of rodents and lorry cleaning (Supplementary Table S1). ${ }^{4}$ Emergency management $=$ variables included are fire alarm, ventilation alarm, risk of noise and source of drinking water (Supplementary Table S1).

total welfare, biosecurity and emergency management reported among farms may contribute to justify the different AMU observed between and within Italian beef farms as described in our previous work ${ }^{27,47}$. Specifically, a significant reduction of frequency of treatment was observed with improved level of welfare making it a potential source of variation of AMU in beef cattle, while no significant results were detected for biosecurity and emergency management.

Reduction of antimicrobials can be achieved if animal health and welfare are not compromised. Hence, it is fundamental to measure parameters considered as reliable indicators of animal health and welfare when running studies on AMU. On average, a high score (76\%) was observed for 'total welfare' among farms indicating a great attention of farmers towards this component for an efficient livestock management ${ }^{12,57}$. Moreover, lower AMU was linked to those batches with improved total welfare conditions, which is in accordance with other studies $^{24,42,58}$. Given the relationship between animal health and welfare ${ }^{3,4}$, the significant lower AMU observed with a high level of welfare made us argue that those batches were also likely to experience an improved health 


\begin{tabular}{|c|c|c|c|c|c|c|c|c|c|}
\hline \multirow[b]{2}{*}{ Effect } & \multirow[b]{2}{*}{ Category } & \multicolumn{2}{|c|}{ TI100it } & \multicolumn{2}{|c|}{ TI100vet } & \multicolumn{2}{|c|}{$\begin{array}{l}\text { HPCIA } \\
\text { TI100it }\end{array}$} & \multicolumn{2}{|c|}{$\begin{array}{l}\text { HPCIA } \\
\text { TI100vet }\end{array}$} \\
\hline & & LSM & SEM & LSM & SEM & LSM & SEM & LSM & SEM \\
\hline \multirow{3}{*}{ Area $A^{2}$} & Low $(<60 \%)$ & $1.38^{\mathrm{a}}$ & 0.48 & $1.16^{\mathrm{a}}$ & 0.43 & $1.05^{\mathrm{a}}$ & 0.45 & $1.21^{\mathrm{a}}$ & 0.57 \\
\hline & Medium (60\% to $80 \%)$ & $1.46^{\mathrm{a}}$ & 0.42 & $1.25^{\mathrm{a}}$ & 0.39 & $0.95^{\mathrm{a}}$ & 0.33 & $0.98^{\mathrm{a}}$ & 0.40 \\
\hline & High $(>80 \%)$ & $1.42^{\mathrm{a}}$ & 0.40 & $1.07^{\mathrm{a}}$ & 0.33 & $0.82^{\mathrm{a}}$ & 0.28 & $0.77^{\mathrm{b}}$ & 0.31 \\
\hline \multirow{3}{*}{ Area $B^{3}$} & Low $(<60 \%)$ & $1.37^{\mathrm{a}}$ & 0.41 & $1.09^{\mathrm{a}}$ & 0.36 & $0.89^{\mathrm{a}}$ & 0.32 & $0.91^{\mathrm{a}}$ & 0.38 \\
\hline & Medium (60\% to $80 \%)$ & $1.47^{\mathrm{a}}$ & 0.44 & $1.23^{\mathrm{a}}$ & 0.39 & $0.98^{\mathrm{a}}$ & 0.35 & $1.04^{\mathrm{a}}$ & 0.43 \\
\hline & High $(>80 \%)$ & NA & NA & NA & NA & NA & NA & NA & NA \\
\hline \multirow{3}{*}{ Area $\mathrm{C}^{4}$} & Low $(<60 \%)$ & NA & NA & NA & NA & NA & NA & NA & NA \\
\hline & Medium (60\% to $80 \%)$ & $1.48^{\mathrm{a}}$ & 0.44 & $1.17^{\mathrm{a}}$ & 0.38 & $0.94^{\mathrm{a}}$ & 0.33 & $0.99^{\mathrm{a}}$ & 0.41 \\
\hline & High $(>80 \%)$ & $1.36^{\mathrm{a}}$ & 0.40 & $1.14^{\mathrm{a}}$ & 0.37 & $0.93^{\mathrm{a}}$ & 0.33 & $0.95^{\mathrm{a}}$ & 0.40 \\
\hline
\end{tabular}

Table 6. Least squares means (LSM) and standard error of the mean (SEM) of the treatment incidence $(\mathrm{TI} 100)^{1}$ for the effects of Area A, Area B and Area C in beef cattle. ${ }^{\mathrm{a}, \mathrm{b}}$ Different superscript letters within each TI100 index and effect indicate significant differences $(\mathrm{P}<0.05)$; NA = no batch felt within the category. ${ }^{1}$ TI100it = treatment incidence 100 for Italy, calculated by using the defined daily dose for animals for Italy based on Italian guidelines of dosage obtained from the Italian database (www.classyfarm.it); TI100vet = treatment incidence 100 for EU, calculated by using the defined daily dose for animals for Europe based on EMA' guidelines of dosage ${ }^{51}$; HPCIA = Highest Priority Critically Important Antimicrobials. ${ }^{2}$ Area $\mathrm{A}=$ farm management and staff training (e.g. feeding, cleaning, $n$. of employees, $n$. of animal inspections; Supplementary Table S1). ${ }^{3}$ Area B = housing (e.g. flooring system, lighting system, hospital pen; Supplementary Table S1). ${ }^{4}$ Area $\mathrm{C}=$ animal-based measures (e.g. respiratory disease, human-animal interaction, aggressive behaviour, lesions, lameness; Supplementary Table S1).

\begin{tabular}{|c|c|c|c|c|c|c|c|c|c|c|c|c|}
\hline \multirow[b]{2}{*}{ Breed } & \multicolumn{2}{|l|}{ TI100it } & \multirow[b]{2}{*}{ P value } & \multicolumn{2}{|l|}{ TI100vet } & \multirow[b]{2}{*}{$P$ value } & \multicolumn{2}{|c|}{ HPCIA TI100it } & \multirow[b]{2}{*}{$P$ value } & \multicolumn{2}{|c|}{ HPCIA TI100vet } & \multirow[b]{2}{*}{$P$ value } \\
\hline & Estimate & SE & & Estimate & SE & & Estimate & SE & & Estimate & SE & \\
\hline Intercept & 0.119 & 0.073 & 0.052 & 0.113 & 0.073 & 0.061 & 0.194 & 0.123 & 0.058 & 0.118 & 0.082 & 0.074 \\
\hline BDA & $0.395^{\wedge}$ & 0.217 & & $0.438^{*}$ & 0.219 & & $0.545^{\star}$ & 0.271 & & $0.401^{\wedge}$ & 0.242 & \\
\hline CHR & -0.173 & 0.143 & & -0.038 & 0.140 & & -0.020 & 0.183 & & -0.116 & 0.147 & \\
\hline FRC & -0.144 & 0.162 & & -0.109 & 0.158 & & -0.093 & 0.204 & & -0.027 & 0.171 & \\
\hline IRC & -0.202 & 0.194 & & -0.274 & 0.195 & & $-0.482^{\wedge}$ & 0.257 & & -0.359 & 0.228 & \\
\hline ITC & $-0.544^{*}$ & 0.164 & & $-0.404^{*}$ & 0.159 & & $-0.500^{*}$ & 0.207 & & $-0.348^{*}$ & 0.176 & \\
\hline LIM & $0.434^{*}$ & 0.150 & & $0.441^{*}$ & 0.147 & & $0.592^{*}$ & 0.192 & & $0.453^{*}$ & 0.159 & \\
\hline SAL & 0.032 & 0.212 & & -0.098 & 0.216 & & -0.123 & 0.277 & & -0.049 & 0.238 & \\
\hline
\end{tabular}

Table 7. Estimate and standard error (SE) of the treatment incidences (TI100) $)^{\mathrm{a}}$ for the effect of breed ${ }^{\mathrm{b}}$ in beef cattle. ${ }^{\text {a }}$ TI100it $=$ treatment incidence 100 for Italy, calculated by using the defined daily dose for animals for Italy based on Italian guidelines of dosage obtained from the Italian database (http://www.classyfarm.it); TI100vet $=$ treatment incidence 100 for EU, calculated by using the defined daily dose for animals for Europe based on EMA' guidelines of dosage ${ }^{51}$; HPCIA = Highest Priority Critically Important Antimicrobials. ${ }^{b} \mathrm{BDA}=$ Blonde d'Aquitaine, $\mathrm{CHR}=$ Charolaise, $\mathrm{FRC}=$ French crossbred, IRC = Irish crossbred, ITC = Italian crossbred, $\mathrm{LIM}=$ Limousine, $\mathrm{SAL}=$ Salers. Statistically different from the intercept $={ }^{\wedge} 0.10<\mathrm{P}<0.05 ;{ }^{\star} \mathrm{P}<0.05$.

status. Indeed, some of the animal-based measures listed in the Area $\mathrm{C}$ of the section total welfare, were used to assess the presence or absence of health indicators such as lameness, lesions and respiratory diseases. Albeit not significant, a lower TI100it value was found with higher level of Area C, thus supporting our assumption that reduced AMU was associated to improved animal health. Similar results were observed by Becker et al. ${ }^{42}$ who found better animal health parameters in farms that followed an improved welfare fattening system, namely 'outdoor veal calf', compared with conventional fattening systems. The authors suggested a reduced AMU as animals were healthier.

Data were also analysed to explore the potential impact of each area of the section 'total welfare' on AMU. The results showed that, despite lower TI100it values were observed with higher level of Area A and C-while the opposite was reported for Area B-these differences were not significant. Hence, we may argue that significant values of TI100 can be detected only when data are combined together, as also suggested by Damiaans et al. ${ }^{59}$ in their study on biosecurity in cattle. They found that total biosecurity score was significantly higher in dairy than beef cattle. However, when single subcategories of biosecurity were tested, only two of them gave significant results (e.g. feed and water and calf management). The authors suggested that while the differences were too small to be significant for each distinct subcategory, the latter revealed their 'hidden difference' only through the calculation of the total biosecurity score. In practice, this may imply that a significant reduction of AMU is possible when all welfare standards of all areas are properly applied on-farm. 
Findings from the current study also showed lower ADG and body weight with better welfare conditions. This is in accordance with the study of Becker et al. ${ }^{42}$ who reported a lower ADG (1.29 vs. $\left.1.35 \mathrm{~kg} / \mathrm{d}\right)$ and dry matter intake, albeit not significant, for veal calves reared under better welfare conditions. The authors explained the resulting lighter carcass weight of these calves either due to a different feeding strategy or to a colder air temperature because they were reared outdoor. Hence, it is likely that the higher energy requirement needed for thermoregulation, contributed to the lower ADG observed for calves reared with improved welfare standards.

High growth rate does not necessary mean that animals are equally experiencing good welfare ${ }^{41}$, emphasising the multifactorial nature of animal welfare ${ }^{60,61}$. This may contribute to further clarify the lower ADG/body weight observed with better welfare conditions and reported in our study. Indeed, the concept of animal welfare goes beyond disease conditions, reproductive health and growth rate, thus implying that only if reproduction or survival are compromised, the welfare of the animals is considered poor ${ }^{62,63}$. Animal welfare is more than that, it is also related to the animal's emotional/mental state. According to the definition given by the World Organisation for Animal Health Terrestrial Code to animal welfare ${ }^{1}$, both the biological functioning and the natural behavioural needs are equally important to evaluate the physical and mental state of an animal ${ }^{2}$.

At first sight, low body weight may appear as a disadvantage of raising beef cattle with high welfare standards. However, potential economic loss that farmers may encounter with a reduced slaughter weight can be balanced by a reduction of antimicrobials cost ${ }^{42}$. Also, targeted-feeding programmes may be a valuable strategy to minimise such a loss. Future research should better investigate this relationship, as the impact of welfare standards and other farm-related variables on performance traits was not the objective of this study.

Statistically significant differences among breeds were observed for AMU, as also reported in our previous study ${ }^{27}$ where breed was identified as an important source of variation of AMU. In addition, results from the current study showed that breeds differed significantly for the score assigned to total welfare. Surprisingly, breeds with high welfare scores were not always those showing lower AMU. It is likely that certain welfare measures may result more/less effective according to the breed, like seen in the study of Magrin et al. ${ }^{46}$ on beef cattle. The authors reported that rubber-covered slatted floors helped to reduce the percentage of animals treated and culled for locomotor disorders only for Limousine breed. In fact, this type of welfare-friendly flooring system was not equally efficient for Charolaise beef breed, likely due to animals' higher weight. This suggests that in order to maximise the positive effect of high welfare standards on AMU, tailored welfare measures must be implemented according to the breed(s) reared on-farm.

The efficacy of biosecurity measures in preventing diseases and improving animal health is widely documented ${ }^{10,34,64}$. Nonetheless, knowledge on the overall level of biosecurity in beef fattening farms is still poorly available and it seems difficult to implement. Data from this study described, for the first time, the level of biosecurity applied on Italian beef fattening farms suggesting room for improvement. Indeed, not only our findings reported a general low level of biosecurity among farms, with a mean score per batch of $24 \%$, but also we realised that none of the batches scored $>80 \%$ - namely as 'high'- which is the category indicating farms with the best conditions of biosecurity. This is in accordance with other studies where despite a general awareness on the importance of biosecurity in ensuring good animal health and performance, it was poorly implemented on-farm ${ }^{5,59,65}$. Damiaans et al..$^{59}$ described a low mean biosecurity score in Belgian cattle farms with specifically veal (39.7) and beef (44.3) scoring lower than dairy (48.6) out of 100 points. Another study on Italian dairy cattle also reported similar results with a mean biosecurity score of $45.8 \%$ out of $100 \%{ }^{54}$. It is possible that farmers are not willing to implement biosecurity measures especially when these are considered costly to apply or if the herd is not experiencing any performance/reproductive loss ${ }^{65-67}$. Also, providing 'easy-to-access' and concrete information on biosecurity levels, which are now lacking for beef cattle, will enable farmers to apply more accurate measures ${ }^{64,68}$. Similar results were also observed for the level of emergency management with the majority of the batches scoring lower than $60 \%$ - namely as 'low' - and only $2.1 \%$ of them scoring more than $80 \%$ while no data were available for the category 'medium'. This likely indicates that Italian beef fattening farms are not adequately prepared to deal with unexpected emergencies such as fires or disruption of the drinking system in the herd.

The general low scores reported in this study may have biased our findings because those farms reporting low AMU were also identified within the category of 'low level of biosecurity'. Therefore, the lack of significant effect found for both biosecurity and emergency management sectors on AMU can likely be justified by the limited sample size of certain categories (i.e. 'medium' and 'high') with a bias of data towards lower scores. Such a shortage of data may also justify the numerically higher TI100 values, albeit not significant, observed with higher biosecurity which is somehow surprising. In fact, different studies showed that increased biosecurity was often associated to lower AMU and better health and welfare conditions of the animals ${ }^{32,34,42}$, thus supporting the idea that improved biosecurity should be a core objective of animal production. The positive correlation found in our study between biosecurity and welfare standards, somehow would strengthen this notion. However, there are also studies that observed few contradictions such as in Pandolfi et al. ${ }^{5}$ who reported a negative impact on mortality, prevalence of lameness and need of more hospitalizations in pigs belonging to the cluster with higher biosecurity score. Whereas, Calderón Díaz et al. ${ }^{69}$ reported that improved levels of certain biosecurity practices related to cleaning and disinfection (e.g. footbaths) were associated to an increased likelihood of PRRS disease. The authors explained the results suggesting that these measures were likely applied a posteriori rather than in a 'preventive' manner. Hence, further research is needed to better clarify this relationship in beef cattle too.

Finally, it is worth to highlight that the assessment of biosecurity was made by scoring those items that are identified as 'external biosecurity'8,59. Indeed, it is likely that a significant reduction of AMU with improved level of biosecurity may be detected only by combining data of both external and internal biosecurity, as observed for the results of total welfare. Laanen et al. ${ }^{33}$ reported a significantly lower treatment incidence only when internal biosecurity was higher, leading in turn to significant results also for the overall biosecurity. According to literature, internal biosecurity seems to play an important role for the reduction of $A M U^{5,33,59}$. For instance, within the practices classified as internal biosecurity, those related to the 'health management' such as isolation of sick 
animals or using of specific boots/clothes for hospital pens only, are essential to avoid contact between healthy and infected animals ${ }^{59}$. The latter, are recognised as major reservoir of infectious diseases ${ }^{70,71}$. This emphasises not only the crucial influence that single 'internal' practices may have on the overall biosecurity score ${ }^{5,33}$, but also the importance of combining internal and external biosecurity measures to obtain a more reliable information.

With this study, we also highlighted both the importance of defining data for farm benchmarking to be used in future research on AMU and the potential limitations of retrospective studies in obtaining reliable information on AMU. Indeed, these studies can have missing values and lack of a specific study design, thus requiring multiple data from different sources or the collection of data in different ways ${ }^{5}$. This was the case of the current study, where data on AMU were available at batch level while animal welfare and biosecurity assessments were made at farm level, whereby potentially explaining the lack of significant results between categories of both biosecurity and emergency management.

\section{Conclusion}

In summary, a wide variation among farms for biosecurity and emergency management was reported. Specifically, while on average a high score $(76 \%)$ was observed for total welfare indicating great attention of farmers towards this component, the level of biosecurity and emergency management in beef cattle was quite low (24 and 39\%, respectively) suggesting room for improvement. Moreover, a significant reduction of AMU was observed with improved level of animal welfare. On the opposite, no significant effect on AMU was observed for biosecurity and emergency management likely due to a bias of data towards lower scores. These results may help to define benchmark data and to address the reduction of AMU in beef industry. For instance, we recommend major focus on strategies to improve both external and internal biosecurity or else targeted animal welfare programmes to satisfy the needs of each farm individually. Further research is still needed to confirm our findings. In fact, data coming from retrospective studies may only provide part of the story, whereas future longitudinal controlled studies will better clarify the relationship between welfare standards, biosecurity practices and AMU by removing other potential confounding factors.

\section{Data availability}

The datasets generated and/or analysed during the current study are not publicly available due to their sensitive nature but are available from the corresponding author on reasonable request.

Received: 26 June 2020; Accepted: 18 November 2020

Published online: 01 December 2020

\section{References}

1. OIE. Introduction to the recommendations for animal welfare. OIE https://www.oie.int/index.php?id=169\&L=0\&htmfile $=$ chapi tre_aw_introduction.htm (2019).

2. Dawkins, M. S. A user's guide to animal welfare science. Trends Ecol. Evol. 21, 77-82 (2006).

3. de Passillé, A. M. \& Rushen, J. Food safety and environmental issues in animal welfare. Rev. Sci. Tech. Off. Int. Epiz. 24, 757-766 (2005).

4. Harley, S., More, S., Boyle, L., O’Connell, N. \& Hanlon, A. Good animal welfare makes economic sense: potential of pig abattoir meat inspection as a welfare surveillance tool. Ir. Vet. J. 65, 11 (2012).

5. Pandolfi, F., Edwards, S. A., Maes, D. \& Kyriazakis, I. Connecting different data sources to assess the interconnections between biosecurity, health, welfare, and performance in commercial pig farms in Great Britain. Front. Vet. Sci. 5, 41 (2018).

6. Henningsen, A., Czekaj, T. G., Forkman, B., Lund, M. \& Nielsen, A. S. Welfare and economic performance at farm level: a quantitative study of Danish pig producers. J. Agric. Econ. 69, 142-162 (2018).

7. Carroll, J. A. \& Forsberg, N. E. Influence of stress and nutrition on cattle immunity. Vet. Clin. N. Am. Food Anim. Pract. 23, 105-149 (2007).

8. Dewulf, J. \& Van Immerseel, F. General principles of biosecurity in animal production and veterinary medicine. In Biosecurity in Animal Production and Veterinary Medicine (ed. Dewulf, J. \& Van Immerseel, F.) 63-76 (CABI, Wallingford, 2018).

9. Ohlson, A. et al. Risk factors for seropositivity to bovine coronavirus and bovine respiratory syncytial virus in dairy herds. Vet. Rec. 167, 201-206 (2010).

10. Stokstad, M. et al. Using biosecurity measures to combat respiratory disease in cattle: The Norwegian control program for bovine respiratory syncytial virus and bovine coronavirus. Front. Vet. Sci. 7, 167 (2020).

11. EFSA. Scientific Opinion on the welfare of cattle kept for beef production and the welfare in intensive calf farming systems. EFSA J. 10, 2669 (2012).

12. Garcia, R. 'One Welfare': a framework to support the implementation of OIE animal welfare standards. OIE Bulletin No.1: Animal Welfare: an Asset for Livestock Production. http://www.oie.int/fileadmin/Home/eng/Publications_\%26_Documentation/docs/pdf/ bulletin/Bull_2017-1-ENG.pdf (2017).

13. Pagel, S. W. \& Gautier, P. Use of antimicrobial agents in livestock. Rev. Sci. Tech. 31, 145-188 (2012).

14. the use of antimicrobials in the livestock sector. Rushton, J., Pinto Ferreira, J. \& Stärk, K. D. Antimicrobial resistance. OECD Food Agric. Fish Pap. 68, 1-37 (2014).

15. Lhermie, G. et al. Economic effects of policy options restricting antimicrobial use for high risk cattle placed in US feedlots. PLoS ONE 15, e0239135 (2020).

16. Aarestrup, F. M. Association between the consumption of antimicrobial agents in animal husbandry and the occurrence of resistant bacteria among food animals. Int. J. Antimicrob. Agents. 12, 279-285 (1999).

17. WHO. Antimicrobial resistance: global report on surveillance. WHO http://www.who.int/drugresistance/documents/surveillan cereport/en/ (2014).

18. Pinto Ferreira, J. Why antibiotic use data in animals needs to be collected and how this can be facilitated. Front. Vet. Sci. 4, 213 (2017).

19. Timmerman, T. et al. Quantification and evaluation of antimicrobial drug use in group treatments for fattening pigs in Belgium. Prev. Vet. Med. 74, 251-263 (2006).

20. EMA. Sales of veterinary antimicrobial agents in 30 European countries in 2016. EMA. https://www.ema.europa.eu/en/docum ents/report/sales-veterinary-antimicrobial-agents-30-european-countries-2016-trends-2010-2016-eighth-esvac_en.pdf (2018).

21. Prescott, J. F. Antimicrobial use in food and companion animals. Anim. Health Res. Rev. 9, 127-133 (2008). 
22. Oliver, S. P., Shelton, E. M. \& Jayarao, B. M. Impact of antibiotic use in adult cows on antimicrobial resistance of veterinary and human pathogens: A comprehensive review. Foodborne Pathog. Dis. 8, 337-355 (2011).

23. Chantziaras, I., Boyen, F., Callens, B. \& Dewulf, J. Correlation between veterinary antimicrobial use and antimicrobial resistance in food-producing animals: a report on seven countries. J. Antimicrob. Chemother. 69, 827-834 (2014).

24. Lava, M., Schüpbach-Regula, G., Steiner, A. \& Meylan, M. Antimicrobial drug use and risk factors associated with treatment incidence and mortality in Swiss veal calves reared under improved welfare conditions. Prev. Vet. Med. 126, 121-130 (2016).

25. Lava, M. et al. Effect of calf purchase and other herd-level risk factors on mortality, unwanted early slaughter, and use of antimicrobial group treatments in Swiss veal calf operations. Prev. Vet. Med. 126, 81-88 (2016).

26. Hommerich, K. et al. Monitoring antibiotic usage in German dairy and beef cattle farms: a longitudinal analysis. Front. Vet. Sci. 6, 244 (2019).

27. Diana, A. et al. Exploring potential risk factors of antimicrobial use in beef cattle. Animal (In press).

28. Bos, M. E. H. et al. Consumption of antimicrobials in pigs, veal calves, and broilers in The Netherlands: quantitative results of nationwide collection of data in 2011. PLoS ONE 8, e77525 (2013).

29. Carmo, L. P. et al. Comparison of antimicrobial consumption patterns in the Swiss and Danish cattle and swine production (2007-2013). Front. Vet. Sci. 4, 26 (2017).

30. Visschers, V. H. M. et al. Swiss pig farmers' perception and usage of antibiotics during the fattening period. Livest. Sci. 162, 223-232 (2014).

31. EIP-AGRI. EIP-AGRI focus group on reducing antibiotics in pig farming: final report. EIP-AGRI. https://ec.europa.eu/eip/agric ulture/en/publications/eip-agri-focus-group-reducing-antibiotics-pig (2014).

32. Ribbens, S. et al. A survey on biosecurity and management practices in Belgian pig herds. Prev. Vet. Med. 83, $228-241$ (2008).

33. Laanen, M. et al. Relationship between biosecurity and production/antimicrobial treatment characteristics in pig herds. Vet. J. 198, 508-512 (2013).

34. Postma, M. et al. Evaluation of the relationship between the biosecurity status, production parameters, herd characteristics and antimicrobial usage in farrow-to-finish pig production in four EU countries. Porcine Health Manag. 2, 9 (2016).

35. Raasch, S. et al. Effectiveness of alternative measures to reduce antimicrobial usage in pig production in four European countries. Porcine Health Manag. 6, 6 (2020).

36. Coyne, L. A. et al. Understanding the culture of antimicrobial prescribing in agriculture: a qualitative study of UK pig veterinary surgeons. J Antimicrob. Chemother. 71, 3300-3312 (2016).

37. Visschers, V. H. M. et al. A comparison of pig farmers' and veterinarians' perceptions and intentions to reduce antimicrobial usage in six European countries. Zoon. Pub. Health. 63, 534-544 (2016).

38. Coyne, L. A. et al. Understanding antimicrobial use and prescribing behaviours by pig veterinary surgeons and farmers: a qualitative study. Vet. Rec. 175, 593 (2014).

39. Ekakoro, J. E., Caldwell, M., Strand, E. B. \& Okafor, C. C. Drivers, alternatives, knowledge, and perceptions towards antimicrobial use among Tennessee beef cattle producers: a qualitative study. BMC Vet. Res. 15, 16 (2019).

40. Calderón Díaz, J. A. et al. Delaying pigs from the normal production flow is associated with health problems and poorer performance. Porcine Health Manag. 3, 13 (2017).

41. Diana, A., Boyle, L. A., Garcia Manzanilla, E., Leonard, F. C. \& Calderón Díaz, J. A. Ear, tail and skin lesions vary according to different production flows in a farrow-to-finish pig farm. Porcine Health Manag. 5, 19 (2019).

42. Becker, J. et al. Effects of the novel concept 'outdoor veal calf' on antimicrobial use, mortality and weight gain in Switzerland. Prev. Vet. Med. 176, 104907 (2020).

43. Gallo, L., De Marchi, M. \& Bittante, G. A survey on feedlot performance of purebred and crossbred European young bulls and heifers managed under intensive conditions in Veneto, northeast Italy. Ital. J. Anim. Sci. 13, 798-807 (2014).

44. Cozzi, G., Ricci, R., Dorigo, M. \& Zanet, D. Growth performance, cleanliness and lameness of finishing Charolais bulls housed in littered pens of different design. Ital. J. Anim. Sci. 4, 251-253 (2005).

45. Cozzi, G., Brscic, M. \& Gottardo, F. Main critical factors affecting the welfare of beef cattle and veal calves raised under intensive rearing systems in Italy: a review. Ital. J. Anim. Sci. 8, 67-80 (2009).

46. Magrin, L., Gottardo, F., Brscic, M., Contiero, B. \& Cozzi, G. Health, behaviour and growth performance of Charolais and Limousin bulls fattened on different types of flooring. Animal. 13(11), 2603-2611 (2019).

47. Diana, A. et al. Use of antimicrobials in beef cattle: an observational study in the north-east of Italy. Prev. Vet. Med. 181, 105032 (2020).

48. Grave, K. et al. The usage of veterinary antibacterial drugs for mastitis in cattle in Norway and Sweden during 1990-1997. Prev. Vet. Med. 42, 45-55 (1999).

49. Persoons, D. et al. Antimicrobial use in Belgian broiler production. Prev. Vet. Med. 105, 320-325 (2012).

50. AACTING. Guidelines for collection, analysis and reporting of farm-level antimicrobial use, in the scope of antimicrobial stewardship. The AACTING network https://aacting.org/swfiles/files/AACTING_Guidelines_V1.2_2019.07.02_54.pdf (2019).

51. EMA. Defined daily doses for animals (DDDvet) and defined course doses for animals (DCDvet). EMA-ESVAC https://www.ema. europa.eu/en/documents/other/defined-daily-doses-animals-dddvet-defined-course-doses-animals-dcdvet-european-surveillan ce_en.pdf (2016).

52. WHO. Critically important antimicrobials for human medicine. WHO https://www.who.int/foodsafety/publications/antimicrob ials-fifth/en/ (2017).

53. Bertocchi, L. et al. Characterization of hazards, welfare promoters and animal-based measures for the welfare assessment of dairy cows: elicitation of expert opinion. Prev. Vet. Med. 150, 8-18 (2018).

54. Ginestreti, J. et al. Consumo di antimicrobici, benessere animale e biosicurezza in 16 aziende di bovine da latte in Lombardia. Large Anim. Rev. 26, 3-11 (2020).

55. Van der Fels-Klerx, H. J., Puister-Jansen, L. F., van Asselt, E. D. \& Burgers, S. L. G. E. Farm factors associated with the use of antibiotics in pig production. J. Anim. Sci. 89, 1922-1929 (2011).

56. McDougall, S., Compton, C. W. R. \& Botha, N. Factors influencing antimicrobial prescribing by veterinarians and usage by dairy farmers in New Zealand. N. Z. Vet. J. 65, 84-92 (2017).

57. Kirchner, M. K. et al. Attitudes and expectations of beef farmers in Austria, Germany and Italy towards the Welfare Quality assessment system. Livest. Sci. 160, 102-112 (2014).

58. Isomura, R., Matsuda, M. \& Sugiura, K. An epidemiological analysis of the level of biosecurity and animal welfare on pig farms in Japan and their effect on the use of veterinary antimicrobials. J. Vet. Med. Sci. 80, 1853-1860 (2018).

59. Damiaans, B. et al. A risk-based scoring system to quantify biosecurity in cattle production. Prev. Vet. Med. 179, 104992 (2020).

60. Ladewig, J. Communication of the welfare status by the animal: Clinical ethology. In Proceedings of Working Sustainable Animal Production Systems. (ed. Ellendorff, F., Moennig, V., Ladewig, J. \& Babiuk, L.) 21-24 (FAL, 2002).

61. Vermunt, J. J. The multifactorial nature of cattle lameness: a few more pieces of the jigsaw. Vet. J. 169, 317-318 (2005).

62. Barnett, J. L. \& Hemsworth, P. H. The validity of physiological and behavioural measures of animal welfare. Appl. Anim. Behav. Sci. 25, 177-187 (1990).

63. McGlone, J. J. What is animal welfare?. J. Agric. Environ. Ethics. 6, 26-36 (1993).

64. Gunn, G., Heffernan, C., Hall, M., McLeod, A. \& Hovi, M. Measuring and comparing constraints to improved biosecurity amongst GB farmers, veterinarians and the auxiliary industries. Prev. Vet. Med. 84, 310-323 (2008). 
65. Brennan, M. L. \& Christley, R. M. Cattle producers' perceptions of biosecurity. BMC Vet. Res. 9, 71 (2013).

66. Smith, D. R. \& Grotelueschen, D. M. Biosecurity and biocontainment of bovine viral diarrhea virus. Vet. Clin. N. Am. Food Anim. Pract. 20, 131-149 (2004).

67. Gates, M. C., Woolhouse, M. E. J., Gunn, G. J. \& Humphry, R. W. Relative associations of cattle movements, local spread, and biosecurity with bovine viral diarrhoea virus (BVDV) seropositivity in beef and dairy herds. Prev. Vet. Med. 112, 285-295 (2013).

68. Sayers, R., Good, M. \& Sayers, G. A survey of biosecurity related practices, opinions and communications across dairy farm veterinarians and advisors. Vet. J. 200, 261-269 (2014).

69. Calderón Díaz, J. A., Costa, M. \& Manzanilla, E. G. Biosecurity practices associated with negative farm status for Mycoplasma Hyopneumoniae, porcine reproductive and respiratory syndrome virus, and swine influenza virus in farrow-to-finish pig farms. ASAS-ADSA 2020 Midwest Annual Meeting. 2nd-4th March 2020, Nebraska, USA (2020).

70. Wells, S. J., Dee, S. \& Godden, S. Biosecurity for gastrointestinal diseases of adult dairy cattle. Vet. Clin. N. Am. Food Anim. Pract. 18, 35-55 (2002).

71. Saegerman, C. \& Humblet, M. F. Biosecurity in veterinary practices and clinics. In Biosecurity in Animal Production and Veterinary Medicine (ed. Dewulf, J. \& Van Immerseel, F.) 453-474 (CABI, Wallingford, 2018).

\section{Acknowledgements}

This study is part of the 'AntibioticFreeBeef' project funded by PSR (Programma di Sviluppo Rurale) of Veneto region (Italy), grant number 3556074 . The authors would like to thank Associazione Zootecnica Veneta (AZoVe, Cittadella, Italy) and farm owners for providing the data. We are also grateful to Arianna Goi, Anna Benedet (University of Padova) and Eliana Schiavon (Istituto Zooprofilattico Sperimentale delle Venezie, Legnaro, Italy) for their support with data management.

\section{Author contributions}

M.D.M acquired funding for this study and together with A.D. designed the study. A.D. and M.P. analysed the data and together with M.D.M., V.L. and E.M. interpreted the data. A.D. conceived the first draft of the manuscript and was responsible for managing the data. M.D.M, M.P., V.L., E.M., G.L.A and L.B. assisted with writing and revision of the manuscript. All authors read and approved the final manuscript.

\section{Competing interests}

The authors declare no competing interests.

\section{Additional information}

Supplementary information is available for this paper at https://doi.org/10.1038/s41598-020-77838-w.

Correspondence and requests for materials should be addressed to A.D.

Reprints and permissions information is available at www.nature.com/reprints.

Publisher's note Springer Nature remains neutral with regard to jurisdictional claims in published maps and institutional affiliations.

(c) (i) Open Access This article is licensed under a Creative Commons Attribution 4.0 International License, which permits use, sharing, adaptation, distribution and reproduction in any medium or format, as long as you give appropriate credit to the original author(s) and the source, provide a link to the Creative Commons licence, and indicate if changes were made. The images or other third party material in this article are included in the article's Creative Commons licence, unless indicated otherwise in a credit line to the material. If material is not included in the article's Creative Commons licence and your intended use is not permitted by statutory regulation or exceeds the permitted use, you will need to obtain permission directly from the copyright holder. To view a copy of this licence, visit http://creativecommons.org/licenses/by/4.0/.

(c) The Author(s) 2020 